\title{
Foreword: Special Issue on Broadening the Perspective on Long-Term Residential Care
}

\author{
Mustafa Z. Younis ${ }^{1,2,3,4}$
}

Published online: 10 May 2017

(C) Springer Science+Business Media New York 2017

I am very pleased to introduce this Special Issue on Broadening the Perspective on Long-Term Residential Care for The Aging International Journal. This Special Issue has articles covering aging topics from different countries around the world. This Special Issue consists of eight papers that address topics from different perspectives of interest to healthcare policy makers, academic researchers and practitioners. The Special Issue Call for Papers was posted and advertised on a national and international scale. All of the papers for this Special Issue were subjected to blind peer review and the authors revised the manuscripts in accordance with the Guest Editor's and reviewers' comments.

The Editor would like to thank Dr. Adnan Kisa, University of Oslo- Norway and Dr. William Ward, University of South Florida for their support, also special thanks to the International Editorial Board of this issue for their service and comments. This issue would never see the light without the support and patience I received from Professor Sue Levkov at the University of South Carolina and Professor Hongtu Chen at Partners HealthCare, in Boston, MA.

The completion of this Special Issue would not have been possible without the many hours contributed by all of the anonymous reviewers who dedicated their time and expertise to help make this Special Issue a reality.

I trust that the reader will find the papers in this Special Issue to be both interesting and provocative, and that they will motivate further research, case studies and demonstrations in the field of Public Health.

Mustafa Z. Younis, Guest Editor

Mustafa Z. Younis

younis99@gmail.com

1 Harvard University Asia Aging Center, Cambridge, MA, USA

2 Health Financing Expert, Institute for Health Metrics and Evaluation, Seattle, WA, USA

3 Global Public Health Expert, Institute for Health Metrics and Evaluation, Seattle, WA, USA

4 School of Public Health, Jackson State University, Jackson, MS, USA 
AD-Hoc International Editorial Board

Fatma Abdulla

Senior Vice Provost

New York University- Abu Dhabi

Abu Dhabi- United Arab Emeritus

Dana A. Forgione,

Professor of Accounting

College of Business

University of Texas at San Antonio

San Antonio, TX

USA

Michael Hartmann, School of Medicine

Professor, School of Medcine

Jena University

Jena, Germany

Zhang Jun

Research Center for Public health

Tsinghua University

Beijing, China

Henry O’Lawrence

Professor, Department of Healthcare Administrations

California State University- Long Beach.

Long Beach, California

USA

Tony Sinay

Professor \& Chair, Department of Healthcare Administrations

California State University- Long Beach

Long Beach, California

USA

William Ward,

Department of Health Policy and Management

College of Public Health

University of South Florida

Tampa, FL

USA

Tarek Yousef

Director, Brookings Institute- Doha Center

Doha, Qatar 


\section{Compliance with Ethical Standards}

Conflict of Interest Mustafa Z. Younis declares no conflict of interest.

Informed Consent As there is no person or personal data appearing in the paper, there is no one from whom a permission should be obtained in order to publish personal data.

Ethical Treatment of Experimental Subjects (Animal and Human) This article does not contain any studies with human participants or animals performed by the author.

Mustafa Z. Younis is an internationally recognized scholar and was a member of the Executive Committee of the International Society for Research of Healthcare Financial Management.

Dr. Younis has authored and published over 200 articles, abstracts and presentations in refereed journals and meetings, and has presented at national and international conferences. Dr. Younis has administrative experience as Senior Advisor for the President at Zirve University, Turkey and as Chair of the Department of Health Policy and Management at Florida International University (FL, USA) where he led the accreditation efforts for the Healthcare Management Program.

Dr. Younis has a history of playing visible roles on the editorial boards of journals as Chief Editor, Guest Editor and Editorial board member of leading journals such as IJMR, JHCF, Inquiry, JHHSA, JPBAFM.

Dr. Younis is a frequent speaker for both academic and professional audiences. His talks often feature his latest research and work in progress as well as cross-industry trends and strategy implications. He has provided workshops and presentation for wide organizations. His research and findings applied to for-profit, non-profit settings, and government.

Dr. Younis has consulted with several organizations on Healthcare Finance, and Economics.

Dr. Younis is often invited to speak about the challenges in the healthcare industry and other related topics to health economics, finance, and research. He has presented topics, such as, healthcare reform, ownership structure, profitability, unit cost, payment system and efficiency in management, at a variety of forums and conferences in Europe, Asia and Middle East. 